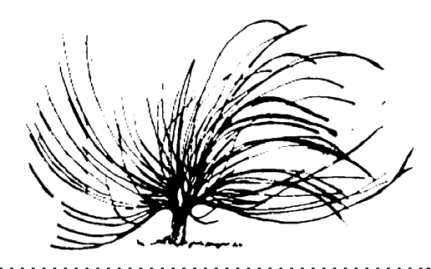

\title{
La importancia de la otredad en la enseñanza de la religión en las escuelas: el gran desafío para el docente
}

\author{
Héctor Alfredo Figueroa ${ }^{1}$ \\ Universidad Nacional \\ Costa Rica \\ hafigueroa7@gmail.com
}

\begin{abstract}
Resumen
Basta mirar alrededor nuestro para descubrir que lo que sucede en las aulas es el mero reflejo de esa sociedad que las circunda. Las relaciones interpersonales, muchas veces dañadas por distintas circunstancias, se diluyen con el devenir de los días, terminando en una ignorancia total hacia los otros o en agresiones cuyo límite no se pueden prevenir. Parece que la asignatura de religión no puede penetrar esas corazas de individualismo y relativismo; por consiguiente, no está dando frutos como pacificadora y generadora de encuentro. Será hora de interpelar nuestras acciones como agentes sociales y educadores, con el afán de lograr una honesta transformación para bien de todos. Pensando en poder asumir nuestro compromiso, se propone, primeramente, reconocernos a nosotros mismos tal cual somos, para luego reconocer al otro y, de esa manera, actuar como verdaderos hacedores de puentes que fomenten el diálogo conducente a la paz.
\end{abstract}

Recibido: 8 de junio de 2019. Aprobado: 28 de octubre de 2019.

http://dx.doi.org/10.15359/rep.15-1.5

1 Docente en escuela secundaria básica y superior. Licenciado en la enseñanza de la educación religiosa (en curso), en la Universidad Nacional de Costa Rica, Escuela Ecuménica de Ciencias de la Religión. Diplomado universitario en Evangelios, Universidad de San Isidro (Bs. As. Argentina), entre otros. https://orcid.org/0000-0002-0429-3758 
Palabras clave: otredad, alteridad, filosofía dialógica, cultura, interculturalidad, multirreligiosidad, interreligiosidad, comunión, paz, deconstrucción, mediación pedagógica, educación inclusiva, equidad, igualdad.

\begin{abstract}
By looking around, it is possible to realize that what happens in the classrooms is the consequence of the society in which it is embedded. Interpersonal relationships, frequently damaged by different circumstances, are weakened as time goes by ending in complete indifference towards other people or aggression that is impossible to prevent. It seems that Religion as a subject cannot tear down these walls of individualism, and consequently, it is not succeeding in its attempt to create peace and bring people together. It is time to question our actions as social agents and educators to achieve a real change for all of us. In order to do this, the first proposal is to recognize ourselves as we are; only then can we recognize the others. In that way, we may act as real bridge builders to motivate the dialogue that leads to peace.
\end{abstract}

Keywords: otherness, alterity, dialogic philosophy, culture, interculturality, multireligiousness, interreligiousness, communion, peace, deconstruction, pedagogical mediation, inclusive education, equity, equality.

\title{
Introducción
}

nte la problemática existente en muchas instituciones educativas, $\triangle$ que no son más que el reflejo de la situación de la sociedad $\mathcal{L}$ en cuanto intolerancia de diversos tipos, individualismo, relativismo, insensibilidad social ante migrantes, pobreza, marginalidad, exclusión, segregación por índole sexual, religiosa, étnica, cultural, política. Es necesario detenernos a reflexionar, como educadores, sobre los posibles caminos por tomar para transformar estas realidades áulicas, favoreciendo el acercamiento entre las personas estudiantes 
y toda la comunidad educativa, en busca de la cohesión y la paz de nuestros pueblos.

Este ensayo presenta una reflexión acerca de la otredad, o sea, el reconocimiento de la existencia del otro como ser que existe en sí y se relaciona con los demás, conjugando su propia realidad tal como es; y la aplicación de la mediación pedagógica que va favoreciendo la interculturalidad y la interreligiosidad hacia un encuentro de personas en actitud inclusiva. Asimismo, se concluirá con algunos lineamientos por seguir para que los responsables de la gestión educativa - desde los políticos, las familias, los educadores y los educandos- puedan replantear sus posturas y tomen un camino de sinodalidad ${ }^{2}$, en busca de fines comunes para el enriquecimiento de relaciones respetuosas en la diversidad.

Es necesario que se interpele a los centros educativos y educadores, acerca de sus funciones y compromisos. ¿Está la educación religiosa preparando a los jóvenes para ser ciudadanos comprometidos? ¿Se está educando para la paz como consecuencia del respeto a la existencia del otro, en su diversidad? ¿Cómo se puede transformar lo hecho u omitido hasta hoy? Desde estos cuestionamientos, se plantea la discusión en las áreas correspondientes, involucrando a los responsables de estas, en una proyección de cambios hacia el futuro inmediato, ya que urge tomar medidas al respecto. La sociedad nos necesita hoy.

Este ensayo dará a conocer, en un primer apartado, la presentación de la otredad desde una definición de diccionario, pero también desde la mirada crítica del filósofo Martin Buber, cuando expone la actitud vincular del concepto doble yo-tú. En un segundo momento, se analizará la cultura, justificándola desde su definición semántica, también como continente de la religión y las relaciones que en aquella se realizan. Por último, reconociendo la otredad como parte esencial constitutiva de la cultura, se propondrá la deconstrucción para interactuar con la mediación pedagógica y, en consecuencia, disponer los medios posibles para generar una educación inclusiva.

2 Se refiere, de esta forma, a la intención de "caminar juntos(as)" alrededor de un tema común. Ya desde Aristóteles, su uso era relacionado con la conjunción de planetas. Proviene del griego бúvodos (sýnodos). 


\section{El otro en la cultura, la religión y la inclusión}

\section{La otredad como tal}

Quisiera priorizar en este ensayo la intención puesta en la otre$d a d$, término en español que se refiere al otro, lo que en el vocablo de base latina - proveniente de alter- se conoce como alteridad. Esto se puede confirmar, además, en las definiciones de ambas palabras, en el diccionario de la Real Academia Española, "condición de ser otro", por lo cual, en este trabajo, serán comprendidas como sinónimos.

Martin Buber, filósofo y escritor judío, austríaco-israelí, quien vivió entre 1878 y 1965 , se destacó en la filosofia dialógica y su pensamiento existencialista por su libro "Ich un $D u$ " (en alemán), que traducido es "Yo y Tú" e implica la esencia de esa idea de diálogo que propone en su filosofía. Insiste en que la característica común de la humanidad es la comunicación y una de sus herramientas es el diálogo.

"El hombre del siglo XXI, no sólo tiene dificultad para encontrarse consigo mismo, sino, su mayor problema es el encuentro con los demás" (Bolaños, 2010, p. 2). Esto señala que esa distancia interpersonal se percibe claramente y lo que es necesario es generar una educación para el encuentro. Este paso requiere, primero, que el individuo salga de sí, reconociéndose, ubicándose en su contexto y desde allí pueda darse cuenta de la existencia del otro.

Bolaños (2010) realiza una extensa investigación acerca de este pensamiento dialógico de Buber y destaca que el "yo" no puede existir ni configurarse sin el "tú"; es necesario fomentar ese momento de encuentro entre ambos, en el cual, se descubrirán aportes insospechados entre los dos. El conocer y respetar la coexistencia ayudaría a construir un pensamiento mediador para generar apertura y diálogo fecundo en la humanidad. Entiendo que debemos redescubrir la capacidad relacional de la gente, ya que eso es el puente entre persona y persona, al ser la relación el problema antropológico más importante en el pensamiento de Buber.

Para que ese diálogo sea fecundo y veraz, es necesaria una disposición a este, a la escucha, a la relación, a ser empático, a vencer los miedos a lo desconocido. No se requiere simplemente un acto comunicacional, sino más bien de comunión. La actitud del que dialoga verdaderamente es la de comprender al otro, no como objeto, sino como a quien "debo responder"; y esto es implicarse responsablemente con el 
otro, sin perder de vista que yo soy "el otro" para aquel. Buber (1993) entiende que la vida religiosa es una vida dialógica, en permanente movimiento de dirigirse $\mathrm{u}$ orientarse a algo o a alguien.

Podemos distinguir tres tipos de diálogo: el auténtico, que es el que considera la existencia del otro en su "ser en sí" tal cual es y se funde en una "reciprocidad vital", me atrevería a decir, en términos de las ciencias biológicas, una simbiosis; el técnico, solo por necesidad de "entendimiento objetivo", y el monólogo disfrazado de diálogo, en el cual se habla consigo mismo y no se reconoce el "tú" (Buber, 1993).

Las "palabras básicas" para Buber (1993) son los pares "yo-tú" y "yo-ello"; el primero cualifica la bipolaridad constitutiva de la conciencia humana y, por lo tanto, se utiliza solamente para la relación entre humanos, mientras que el segundo se deja para la relación con los demás seres del mundo.

La presencia de uno ante el otro es lo que en la conciencia humana se percibe como existencia y ante eso se busca un nexo para el vínculo de esas presencias mutuamente acordadas y respetadas, con un "entre" que permite que sea fehaciente la interrelación. Este acto de vinculación es extremadamente necesario para la existencia humana, no solo para existir en sí, sino "entre sí". Esto tan esencial para la vida constituye un acto "humanizador", o sea, el yo se hace humano con otro humano, ya que escapa de su inmanencia, trasciende de su individualismo y pasa a existir con el otro yo, es decir, el tú.

En términos actuales, podemos terminar con una expresión muy coloquial como la que se usa cuando la población asume cierto compromiso con alguien, - ya sea desaparecido, asesinado, proscripto y que tiene apoyo popular; en esos casos, hemos escuchado, aquí en Argentina, ante la muerte (asesinato comprobado) del fiscal Nisman, que investigaba cuestiones muy comprometedoras sobre gente importante-, con hashtags utilizados en redes sociales como "\#todossomosnisman"; de esta manera - por las marchas organizadas para pedir justicia esclarecedora-, se dio a conocer al mundo. Hoy, en esta situación y como reclamo para que no perdamos de vista la humanidad y la importancia del otro, podríamos utilizar (otro hashtag) algo así como: "\#todossomoselotro"; ¿necesitaremos hacer marchas para reclamar por el otro?, ¿o podemos ir simplemente al encuentro del otro?

Para Buber (1993), esa responsabilidad con el otro se traduce en un tipo de amor que no está en el yo, sino entre el yo y el tú con calidad 
dialógica, sale del yo hacia el otro y llega a deteniéndose en él, como amor permanente.

Para mí, este punto es ineludible, no se puede construir una sociedad — y me refiero a la ciudadana tanto como la escolar — con base en individualismos, o sea, haciendo omisión de las partes que se suman en un todo. Es necesario humanizar la existencia propia con la presencia del otro.

\section{La cultura como continente del fenómeno religioso y la manifesta- ción de la interculturalidad}

Entendemos por "cultura" un compuesto de todo aquello que hace el humano en un espacio de tiempo determinado y en un lugar, en consonancia con otros como él. Según una de las definiciones del diccionario de la RAE, leemos que expresa textualmente: "Conjunto de modos de vida y costumbres, conocimientos y grado de desarrollo artístico, científico, industrial, en una época, grupo social, etc.”. Entonces, podemos inferir que la religión es parte de ese acervo con que se fue tejiendo la historia de un pueblo determinado y hablar de ella como algo escindido o disociado de esa sociedad no tiene sentido, ya que entendamos, también, que las personas somos un todo, estamos integradas con todo aquello que el pasado y las relaciones personales fueron escribiendo en nuestra historia, incluido lo religioso.

Podemos decir, en otras palabras, que, en nuestros pueblos latinoamericanos, el cristianismo católico traído por los colonizadores en una etapa y luego por los inmigrantes, antepasados de muchos de nosotros, tuvo su gran influencia en nuestra civilización - muchas veces incivilizadamente-, imponiéndose sobre creencias locales y religiones autóctonas. Muy lejos estaba aquello de la "inculturación" que el papa Pablo VI dejó interpretar implícitamente en el capítulo II de Gaudium et Spes, lo cual, obviamente, luego del Concilio Ecuménico Vaticano II (1962-1965) se empezó a tomar más o menos en serio en la Iglesia.

Esa inculturación no es adoptar ciertos ropajes como disfraces o algunas músicas nativas; es asumir la realidad de la cultura y entregar allí el evangelio. El mejor testimonio se encuentra - para los cristianos - observando a los discípulos de Jesús que partieron con una única forma de celebrar "la cena del Señor" y de contar sus palabras, pero se adaptaron a las costumbres de los pueblos a los que llegaron. 
Luego, con el tiempo, arribaron otras confesiones cristianas y otras religiones; también empezaron a recuperarse y resurgir algunas creencias de los pueblos originarios de estas tierras - aunque tal vez no todoshasta la multiplicidad de credos que hoy colorean nuestras naciones.

En este contexto multirreligioso, existen distintos tipos de relaciones entre las diversas creencias, algunas muy amigables y otras con cierta tirantez o hasta la indiferencia. En términos lingüísticos, la multirreligiosidad habla solamente de la existencia de muchas religiones, sin indicar si hay o no relación alguna; progresando hacia la interreligiosi$\mathrm{dad}$, me expreso doblemente en el sentido de "progreso", ya que - no solo es un paso a otro tipo de relación - creo que es un avance de calidad importantísimo para la humanidad el diálogo entre esas religiones. Así mismo, ese peso de la religión de años construyó un pensamiento social heredado hoy día, con el que se mide — en cierta forma - la moral social.

Aunque el evangelio - que las iglesias cristianas promueven entre sus fieles- no es moralizante (Ronchi, 2016), se ha moralizado durante tantos años - sería más explícito remarcado durante tantos siglos - de tradición cristiana cada vez más anquilosada. Esa esclerocardia o dureza del corazón se dio como consecuencia de priorizar libros de espiritualidad privada o congregacionales, por sobre el Evangelio sencillo de Jesús; diríamos, en términos bíblicos, que "se ha perdido la miel de la Palabra de Dios" y han quedado estructuras vacías que no promueven la fe.

Ante este panorama, en muchos lugares de nuestra tierra latinoamericana, aún se impone el catolicismo como la única religión, para dar a conocer su fe, especialmente, en ambientes escolares.

Pero, sin desconocer la riqueza de nuestro pasado, hoy, nos debemos poner en diálogo sincero y fecundo con el "otro creyente" y el "otro no-creyente", sin violentar su libertad ni colonizar sus creencias; asumir los errores del pasado - aunque estuvieran en manos de otros, somos sus herederos en alguna medida - y saber pedir perdón para sanar viejas heridas. Indudablemente, al entrar en un diálogo intercultural, también se lleva consigo - como fue expresado - el acervo religioso. Esto, entonces, me atrevo a decir, es un encuentro simultáneo entre culturas, religiones, creencias, no-creencias, esperanzas, sueños, motivaciones, reclamos, políticas, etc., en definitiva, todos los parámetros que componen y completan el "hacer cultural" de los pueblos. 
El teólogo y sacerdote católico de origen suizo Hans Küng (2003), en un reportaje, se refirió a que "No habrá paz entre las naciones, sin paz entre las religiones" ${ }^{\prime 3} \mathrm{y}$, con base en esto, creo que es de suma importancia dejar de lado los fundamentalismos de todo tipo, ya que los "... ismos" no son otra cosa que extremismos y, hasta ahora, la historia no me ha contado grandes cosas sobre estos.

Desde esta mirada abierta y respetuosa, estoy seguro de que podemos construir espacios en la educación, reconociendo la importancia de la alteridad de las personas y de la de las culturas como tales, con sus riquezas y limitaciones, con el fin de dar un paso adelante en mejorar la comunicación y, por consiguiente, la educación para la comunión de nuestros pueblos.

Se trata de dar un paso firme, sereno y seguro, dejando atrás el dogmatismo proselitista que no promueve la fe porque coarta la libertad, avanzando hacia un diálogo intercultural (e interreligioso) testimonial.

Este caminar debe ser acompañado por quienes, de alguna manera, buscan incansablemente esa riqueza de la otredad representada en la cultura y la religión, para un mundo de paz; ese acompañante deberá ser un pedagogo inclusivo y liberador.

\section{La mediación pedagógica como herramienta eficiente de inclusión}

Tomando las apreciaciones de los puntos anteriores - la alteridad y la interculturalidad - la pedagogía será, entonces, la mediadora entre los pueblos, entre los distintos saberes, entre los individuos, para lograr, así, una educación inclusiva. Podría transformarse en la maestra del diálogo.

Para tal efecto, una pedagogía colonizadora como la actual no sería efectiva en estos términos deseados. Será necesario realizar los análisis correspondientes, al proponerse la "deconstrucción"4 de dichos paradigmas, teniendo la habilidad de ver adecuadamente las problemáticas y potencialidades en las relaciones dentro de las instituciones educativas y, sobre todo, en el acto de enseñanza y aprendizaje, con el afán de "reconstruir" caminos pedagógicos nuevos, flexibles, más

3 En un reportaje realizado por Clara Blanchar, para el diario El País, en Barcelona, 2003, se expresó: "no habrá paz entre las naciones sin paz entre las religiones" y "no habrá paz entre las religiones sin diálogo entre las religiones".

4 Término acuñado por Jacques Derrida, filósofo argelino-francés, quien propone — en vez de una destrucción - un desarmar respetuoso, para rescatar lo que sirve y cambiar lo necesario. 
amplios, fronterizos 5 , de calidad. Podemos entender, entonces, que "la educación inclusiva $[\ldots]$ se define como un instrumento de justicia y de cohesión social" (Armijo-Cabrera, 2018, p. 8).

Existe un nuevo problema presentado en el contexto social actual, que no favorecería este aprendizaje mutuo entre las culturas, religiones, valores, etc.; "Knight y Pearl (2000) consideran que la celebración posmoderna de las diferencias lleva a encerrarse en sus identidades y constituye un obstáculo para la comunicación" (Armijo-Cabrera, 2018, p. 9) y sabemos que esta es necesaria para la comunión planteada. Por algún motivo necesario ante la equidad, hoy se reclaman los derechos de muchas minorías antes oprimidas, pero, una vez que estos se exacerban, se juega en contra de esa lucha cuando se autoexcluyen, segregando a los que son diferentes; se percibe un doble discurso con frases como "entre ser o pertenecer" y "somos todos iguales".

Esa dicotomía es disociable, separa, propone la no-aceptación del otro, por lo tanto, el respeto por la otredad no podrá ser un plan para apaciguar y transformar la sociedad. Ese caldo de cultivo hoy fermenta como levadura, promoviendo divisiones en nuestra sociedad; antes eran unos, ahora son los otros $\mathrm{y}$, sin más remedio, esa división social que tenemos se traslada indefectiblemente a nuestras aulas.

De alguna manera, la marginalización puede ser fruto de las culturas dominantes, pero, también, de las culturas dominadas pensadas a sí mismas como automarginadas. En la educación inclusiva, la participación democrática en el aula va a favorecer el ejercicio de la no-homogeneización del grupo y el respeto por la diversidad, sin eufemismos.

«El concepto de educación inclusiva se basa en un principio de "equidad" en pos de la igualdad futura mediante un proceso lineal [...]» (Armijo-Cabrera, 2018, p. 14). En este punto, no quiero dejar pasar el uso incorrecto del término, cuando se plantea con pedir "igualdad"; sin entender que la diversidad es riqueza. Sí, estoy de acuerdo con pedir "igualdad de oportunidades", pero defender y valorar las diferencias es muy bueno, ya que "permite legitimar una competencia regulada considerada sana y justa" (Armijo-Cabrera, 2018, p. 14).

5 Referidos al pensamiento de Giroux, en el que los docentes deben facilitar al educando el acceso provocativo, para traspasar las fronteras establecidas por el sistema. 
Para dejar un ejemplo de discusiones complejas, en el plano educativo, de lo que significa inclusión, me remito una vez más a mi país, la Argentina, en la que aún hoy existe una gama colorida de opiniones -incluso algunas muy antagónicas - acerca de la educación sexual en las escuelas. Lo anterior, con el fin de visualizar cómo el peso de las religiones resalta ante el pensamiento de la retórica oficial sobre promover o no "la igualdad de derechos entre las múltiples identidades de género" contra la "fuerte insistencia en la ley divina como norma universal y objetiva" (Esquivel, 2013, p. 157) propugnada por las creencias cristianas e incluso -últimamente (pero en menor medida) - la musulmana y la judía.

Para este punto, puedo transmitir un diálogo mantenido con un colega catequista en plena batalla librada en nuestro país acerca de la despenalización del aborto. Él, desde su antropovisión, intentaba, a través de una red social, invitar a todos a desistir de la propuesta de abortar, ya que Dios es el dador de vida y, por lo tanto, el único que "la puede quitar" (esta última expresión es de un cristianismo arcaico, pues sabemos, desde la teología, que Dios no envía enfermedades, castigos o muerte, sino que son procesos naturales o fortuitos). Mi planteo ante esa aseveración fue una analogía sobre las distintas lenguas, que un mensaje - por más fidedigno y bienintencionado que pudiera ser- debe ser claro para el receptor, pero, si quien recibe ese mensaje no habla mi idioma, difícilmente me entenderá; entonces, ¿no será que los cristianos tendremos que dejar de pensar que todo el mundo sabe de lo que estamos hablando y usar un lenguaje comprensible? De esta manera, "traduciendo" nuestra cosmovisión y sin imposición, estamos "visualizando" la existencia del otro (o sea la otredad) y, por ende, su cultura; así, entrando en vínculo con el otro, podemos acompañar su aprendizaje y a la vez aprender con él.

\section{Conclusión}

La educación religiosa deberá educar para la paz de un mundo diverso, no solamente para una única concepción afín a ella, mirando al otro a los ojos, confiando, viendo qué hay de "bueno y verdadero" en lo que el otro propone; de tal modo, lograremos comprometernos como ciudadanos participativos en la búsqueda del bien común. La idea es pasar de humano como sustantivo a "ser" humano con las características de un verbo, que es acción; por lo tanto, "ser" humano es 
descubrirnos en la "casa común", dejar de "sobrevivir" o "pernoctar" y pasar a "habitarla", o sea, "transformar para vivir".

Tenemos que entender que estamos de paso, es por un tiempo que se nos presta un pedazo de tierra, esa humildad de la sabiduría ancestral y el reconocimiento de lo efímero de nuestra existencia deberían ser más que suficientes para bajar al humus, a la tierra y entrar descalzo en el misterio que es el otro.

Propongo que colegas, alumnos y familias asumamos una educación inclusiva que a la vez sea liberadora, fronteriza y audaz, con la que se rompa lo establecido, buscando nuevos horizontes. Es preciso permitirnos soñar, diseñar, cambiar el contexto desagradable, para "habitar" este pedazo de historia que nos toca vivir; y que, desde los nuevos saberes logrados por las dimensiones extradisciplinar6 y postdisciplinar 7 (Ocampo, 2018) que llevan a investigar en la diáspora epistémica, podamos enriquecer la propia cultura, saliendo de nuestra zona de confort, emprendiendo un viaje hacia el otro, la cultura — religión incluida- y nuevos conocimientos.

Cuando me refiero a pedagogía inclusiva del "otro" (que puedo ser yo), quiero decir que no basta con integrar, o sea "hacerle un lugar", sino hacerlo parte del todo, que sea uno más. También quiero hablar sobre la característica liberadora de esta pedagogía, entiendo que es un enorme desafío y hasta podría decir una aventura poder soltar cadenas, $\mathrm{y}$, al decir esto, me planteo si estamos en condiciones de salir del fondo de la caverna (me refiero a la alegoría de la caverna de Platón), si hay docentes audaces quienes quieran transformarse en aquellos que les ayuden a sus alumnos a soltarse de los grilletes que los aprisionan y los retienen viviendo una proyección de la realidad. Me pregunto si hay familias que permitan que sus hijos traspasen las fronteras de lo epistémico y se involucren emocionalmente en la búsqueda del conocimiento.

Y sobre todo, una pregunta tal vez incómoda. ¿Habrá políticos que corran el riesgo de generar políticas de Estado — en vez de políticas partidarias - en pro de una educación verdaderamente transformadora, que trascienda su período de gobierno? Para esto, se requerirá que dialoguen y eso nos llevará unos renglones atrás, con el fin de repensar

6 Posee la capacidad de conectar campos alejados en su actividad científica, entrando en contacto a través de determinados objetos y tópicos analíticos.

7 Orienta su actividad hacia la consolidación de nuevos modos de lectura y abordaje de la realidad. 
la importancia del otro. El otro, cualquier otro; del mismo partido o de otro, de la misma religión u otra, de esta etnia o de aquella.

La tarea principal y primera es dejar las apariencias y trabajar en el fondo de las cosas, superando la cultura de la superficialidad o de maquillaje actual, solo así se podrá transformar verdaderamente y formar personas capaces de transformar en un movimiento permanente de avanzar sin atropellar, crecer sin romper, entrar sin invadir.

\section{Referencias}

Armijo-Cabrera, M. (2018). Deconstruyendo la noción de inclusión: un análisis de estudios, políticas y prácticas en educación. Revista Electrónica Educare, 22 (3), 1-26. https://doi.org/10.15359/ ree.22-3.8

Blanchar, C. (2003). El teólogo Hans Küng asegura que no habrá paz entre las naciones "sin paz entre las religiones". Diario El País de Barcelona. Recuperado de https://elpais.com/diario/2003/11/12/ sociedad/1068591614_850215.html

Bolaños, R. (2010). Elementos de alteridad y convivencia social a partir de la Filosofía Dialógica de Martin Buber. Sophia: Colec. de Fil. de la Educ., 8, 11-31 Recuperado de https://dialnet.unirioja.es/ servlet/autor? codigo $=4234999$ \#ArticulosRevistas

Buber, M. (1993). Il Principio Dialogico e altri saggi, trad. it. di A. M. Pastore, con un saggio introduttivo, e apparato critico e commento di A. Poma. Milano: Edizioni San Paolo.

Concilio Vaticano II. (1965). Gaudium et Spes. Constitución Pastoral sobre la Iglesia en el mundo actual. Buenos Aires: Ediciones Paulinas.

Diccionario de la Real Academia Española. (2018). Recuperado de https://dle.rae.es $/$ ?w=diccionario

Esquivel, J. (2013). Narrativas religiosas y políticas en la disputa por la educación sexual en Argentina. Revista Cultura \& Religión, 7(1), 140-163. Recuperado de http://www.revistaculturayreligion.cl/ index.php/culturayreligion/article/view/371/319

Ocampo, A. (2018). Condiciones de producción de la Educación Inclusiva. Revista Pedagógica, 20 (45), 134-161. http://dx.doi. org/10.22196/rp.v20i45.4606 
Ronchi, E. (2016). Jesús no es moralista, nosotros hemos moralizado el Evangelio. Meditaciones en los Ejercicios Espirituales que dio al Papa Francisco y a la Curia. Agencia de noticias Zenit del Vaticano. Recuperado de https://es.zenit.org/articles/ jesus-no-es-moralista-nosotros-hemos-moralizado-el-evangelio/ 
